\title{
Café convencional versus café orgânico: perspectivas de sustentabilidade socioeconômica dos agricultores familiares do Espírito Santo ${ }^{1}$
}

\author{
Haloysio Miguel de Siqueira ${ }^{2}$, Paulo Marcelo de Souza ${ }^{3}$, Niraldo José Ponciano
}

\section{RESUMO}

Esse artigo enfoca a viabilidade de investimento na produção de café arábica, no Estado do Espírito Santo, comparando os sistemas convencional e orgânico, para identificar o que proporciona maior sustentabilidade socioeconômica aos produtores familiares. Os métodos de avaliação econômica utilizados foram o valor presente líquido, a taxa interna de retorno e o tempo de retorno do capital investido. Também foi feita a análise de sensibilidade. Demonstrou-se que ambos os sistemas de produção foram viáveis, mas, observou-se a grande dependência de recebimento do prêmio para viabilizar o cultivo orgânico, compensando a sua menor produtividade. Além disso, o preço recebido foi a variável que exerceu a maior influência na rentabilidade dos cafeicultores familiares. Concluiu-se que, assegurada a eficiência econômica e ecológica do sistema orgânico, o desafio é aperfeiçoar a sua eficiência técnica, para que possa contribuir com a sustentabilidade socioeconômica dos cafeicultores familiares.

Palavras-chave: Sistemas de produção de café, agricultura familiar, avaliação econômica.

\section{ABSTRACT}

\section{Conventional coffee versus organic coffee: prospects for socioeconomic sustainability of family farmers in the state of Espírito Santo}

This paper focuses on the feasibility of investment in production of arabica coffee in the state of Espírito Santo, Brazil, comparing conventional and organic systems, to identify which provides greater social and economic sustainability for family farmers. The methods of economic analysis used in the study were net present value, internal rate of return and payback period. The sensitivity analysis was also performed. It was demonstrated that both production systems were viable, but there was a large dependence on receiving the award for achieving organic farming, offsetting its lower productivity. Moreover, the price received was the variable with the greatest influence on the profitability of coffee farmers. The results led to the conclusion that provided the economic and ecological efficiency of the organic system, the challenge is to improve its technical efficiency to contribute to the socioeconomic sustainability of the family farmers.

Key words: Coffee production systems, family agriculture, economic analysis, sustainability.

\footnotetext{
Recebido para publicação em março de 2010 e aprovado em dezembro de 2010

${ }^{1}$ Esse artigo tomou como base, parcialmente, a tese de doutorado do $1^{\circ}$ autor do artigo.

2 Engenheiro-Agrônomo, Mestre. Centro de Ciências Agrárias, Universidade Federal do Espírito Santo, Caixa Postal 16, 29500-000, Alegre-ES, Brasil. haloysio@cca.ufes.br ${ }^{3}$ Engenheiro-Agrônomo, Doutor. Universidade Estadual do Norte Fluminense, UENF, CCTA/LEAG. Av. Alberto Lamego, 2000, 28013-600, Campos dos Goytacazes, RJ, Brasil. pmsouza@uenf.br, ponciano@uenf.br
} 


\section{INTRODUÇÃO}

O debate atual sobre a sustentabilidade da agricultura no Brasil vem apontando preocupações-chave, como a necessidade de geração e distribuição de renda para todas as famílias rurais, bem como a garantia de acesso à infraestrutura e aos serviços sociais que condicionam a cidadania, no limite da capacidade de suporte ambiental, sem comprometer as condições de dignidade para as gerações futuras.

Nesse sentido, a produção agrícola deveria conciliar o abastecimento interno (segurança alimentar) com a integração competitiva e soberana à economia internacional, dentro do sistema de alimentos, fibras e biomassa, considerando os seguintes aspectos: quantidade (produtividade) e qualidade dos produtos, diversificação de culturas, dependência mínima de insumos externos e agregação de valor (agroindustrialização, atributos culturais/regionais, sociais/trabalhistas e ecológicos). A viabilidade econômica do processo produtivo é muito importante, de modo a proporcionar o retorno sobre o capital investido. Devem ser avaliados os benefícios e os custos do projeto agrícola, antes mesmo de sua implantação.

Atualmente, o Brasil é líder mundial, na produção e na exportação de café e segundo colocado, no consumo. $\mathrm{O}$ Estado do Espírito Santo, que é focalizado neste artigo, responde por $24 \%$ (média das safras 2008 e 2009) da produção nacional, sendo o segundo maior estado produtor, somando-se os cafés conilon e arábica, e o terceiro em café arábica 5 . De acordo com Ferrão et al. (2008), o café é produzido em 77 dos 78 municípios capixabas, abrangendo mais de $65 \%$ das propriedades rurais. São cerca de 400.000 pessoas ocupadas, direta ou indiretamente, na cafeicultura, contribuindo com mais de $35 \%$ do PIB agrícola do Espírito Santo. Predomina a produção em regime familiar, com tamanho médio das lavouras em torno de 9,4ha.

Observa-se que a cafeicultura assume enorme importância, tanto na geração de postos de trabalho e de renda no campo, contribuindo para evitar o êxodo rural, como na obtenção de divisas para o país. Assim, a cafeicultura brasileira deve ser analisada não somente quanto a sua eficiência tecnoprodutiva, mas, também, no que tange a sua eficiência socioeconômica e seus impactos ambientais, de acordo com a concepção de sustentabilidade exposta.

Entretanto, nos últimos anos, a viabilidade econômica da cafeicultura brasileira vem sendo ameaçada, principal-

\footnotetext{
${ }^{5}$ Segundo a CONAB, a produção nacional foi de 45,99 milhões de sacas, na safra 2008 , e foi estimada em 39,47 milhőes de sacas, na safra 2009 (quarta estimativa - dez/2009). A média da produção de café arábica nestas safras foi de 32,17 milhões de sacas, sendo a participação do Espírito Santo igual a 8,5\%
}

mente a de café arábica, apesar da recuperação nas cotações internacionais do produto. A rápida ascensão de novos países concorrentes, como é o caso do Vietnã, e a união dos países da América Central para se colocarem como centro de referência na produção de cafés de qualidade superior, revela as condições de risco e incerteza da atividade cafeeira (Herszkowicz, 2009).

Por outro lado, nota-se o crescimento da cafeicultura orgânica, que é considerada ambientalmente mais sustentável que a convencional, como uma nova oportunidade de mercado. Segundo Giomo et al. (2007) essa cafeicultura representa $0,3 \%$ da área total de café, no Brasil, com cerca de 200 produtores, tendo apresentado crescimento de 5\% ao ano, no período de 2000 a 2006. A exportação brasileira de café orgânico, entre outubro/ 2005 e junho/2006, foi de 6.874 sacas. O preço médio foi US\$ 208,32/saca, superior em US\$ 89,00 ao do café convencional, sendo que cerca de $80 \%$ da produção brasileira é exportada, principalmente para o Japão, os Estados Unidos e a Europa (Giomo et al., 2007). Diante dos preços mais altos, questiona-se até que nível esse diferencial de preço deve ser mantido para não comprometer a viabilidade do sistema orgânico.

Por isto, tornam-se cada vez mais necessários estudos que analisem a viabilidade econômica da cafeicultura. Entre os estudos já realizados e que procederam a análises comparativas entre os sistemas de cultivo convencional e orgânico, podemos citar Carmo \& Magalhães (1999), Sarcineli \& Rodriguez (2006) e Caixeta et al. (2009).

Carmo \& Magalhães (1999), analisando três propriedades produtoras de café orgânico, na Zona da Mata de Minas Gerais, em comparação com o sistema convencional (baseado em dados médios regionais, fornecidos por instituições atuantes no meio rural), demonstraram que dois dos três sistemas orgânicos tiveram melhor desempenho econômico, com elevadas relações custo/benefício. E concluíram que a competitividade dos sistemas orgânicos foi decorrente da eficiência de mercado, diante de preços diferenciados muito favoráveis, pois as produtividades destes sistemas foram menores, embora os gastos efetivamente desembolsados pelos produtores também tenham sido.

Sarcinelli \& Rodriguez (2006) analisaram três sistemas de produção cafeeira, na região da Média Mogiana do Estado de São Paulo, sendo dois sistemas convencionais (um deles com baixa mecanização) e um agroecológico (orgânico). Esses autores concluíram que o sistema agroecológico utilizou mais intensivamente os recursos naturais renováveis e reduziu, consideravelmente, a dependência de insumos externos, com consequente redução nos custos finais de produção. Também proporcionou rentabilidade satisfatória, de $27 \%$, mesmo com menor produtividade da lavoura. Mas, não gerou mais empregos

Rev. Ceres, Viçosa, v. 58, n.2, p. 155-160, mar/abr, 2011 
que os sistemas convencionais e teve pouca produção de alimentos para autoconsumo.

Já Caixeta et al. (2009) estudaram onze propriedades, também na Zona da Mata de Minas Gerais, sendo cinco orgânicas e seis convencionais, no ano de 2006. Constataram que a cafeicultura orgânica apresentou menor produtividade e menor rentabilidade do capital em relação à convencional, mas igualou-se na relação custo/benefício. De outro lado, segundo eles, a cafeicultura orgânica "apresentou maiores médias de receita bruta e líquida, mesmo tendo custo de produção maior, uma vez que, teve o custo compensado pelo maior preço médio de venda do café". E concluíram que todas as propriedades analisadas obtiveram rentabilidade suficiente para o desenvolvimento econômico sustentável da exploração.

A Companhia Nacional de Abastecimento - CONAB, por sua vez, faz monitoramento periódico dos custos de produção do café, nas principais regiões produtoras do país. Os dados divulgados ${ }^{6}$, para o café arábica, referentes à safra 2009/2010, revelam que o custo operacional mais elevado foi no município de São Sebastião do Paraíso-MG, estimado em $\mathrm{R} \$ 325,06$ por saca, considerando uma produtividade média de $23 \mathrm{sc} / \mathrm{ha}$. Já o município de Venda Nova do Imigrante-ES apresentou o menor custo operacional, estimado em $\mathrm{R} \$ 233,56$ por saca, com produtividade média de $24 \mathrm{sc} / \mathrm{ha}$. Podem-se citar, ainda, os custos em Manhuaçu-MG, estimados em R \$254,89 (com 24sc/ ha), e em Franca-SP, estimados em R \$292,25 (com 25sc/ ha), entre outros municípios.

O presente artigo enfoca a viabilidade de investimento na produção de café arábica, em regime familiar, no Estado do Espírito Santo, comparando os sistemas convencional e orgânico, de modo a identificar o sistema mais adequado aos agricultores familiares capixabas, ou seja, com maior sustentabilidade para esses agricultores.

\section{MATERIAIS E MÉTODOS}

\section{Avaliação econômica}

Os métodos de avaliação econômica utilizados foram o valor presente líquido, a taxa interna de retorno e o tempo de retorno do capital investido. Também foi feita a análise de sensibilidade.

O método do valor presente líquido (VPL) baseia-se na transferência, para o presente, de todos os fluxos de caixa esperados no projeto, descontados a uma determinada taxa de juros (taxa de desconto ou taxa mínima de atratividade). De outra forma, o VPL de um projeto de

Disponíveis em: http://www.conab.gov.br/conabweb/download/safra/ custosproducao cafearabica xls. Esses dados se referem aos custos estimados par subsidiar as decisões de política agrícola na safra 2009/2010, com base numa matriz de coeficientes técnicos e no vetor de preços dos fatores (preços médios praticados em cada região enfocada). investimento pode ser definido como a soma algébrica dos valores descontados do fluxo de caixa a ele associado. Ou seja, é a diferença entre o valor presente das receitas e o valor presente dos custos (Lapponi, 2000).

A fórmula algébrica do VPL é expressa por:

$$
V P L=-I+\sum_{t=1}^{n} \frac{F C_{t}}{(1+j)^{t}}
$$

Onde: I é o investimento de capital na data zero (registrado com sinal negativo por ser um desembolso); $\mathrm{FC}_{t}$ representa o retorno na data $t$ do fluxo de caixa; $n$ é o prazo de análise do projeto; e, j é a taxa mínima de atratividade.

Juntamente com o VPL, utilizou-se a taxa interna de retorno. A taxa interna de retorno (TIR) representa uma rentabilidade limítrofe entre a viabilidade e inviabilidade do investimento. Matematicamente, a TIR é a taxa $\left(j^{*}\right)$ que torna o valor presente líquido do projeto igual a zero (Lapponi, 2000), conforme a seguinte expressão:

$$
0=-I+\sum_{t=1}^{n} \frac{F C_{t}}{\left(1+j^{*}\right)^{t}}
$$

Já o "payback”, ou período de retorno do capital, é um indicador que mede o tempo necessário para que um projeto recupere o capital investido. É aplicável, sem restrições, a projetos convencionais de investimento, isto é, aqueles que apresentem um fluxo de caixa com as seguintes características:

$$
F_{o}<0 \text { e } F_{1}>0, \quad i=1, \ldots, n .
$$

em que $F_{i}$ é o fluxo de caixa no ano i, definido pela diferença entre as entradas $\left(B_{i}\right)$ e saídas $\left(C_{i}\right)$ do projeto.

Para sua obtenção verificou-se, inicialmente, entre quais períodos o saldo acumulado dos fluxos de caixa do projeto (em valor presente) trocou de sinal, passando a ser positivo. Depois, por meio de interpolação linear, calculou-se o tempo exato em que ocorreu o saldo zero no fluxo, que marca o período necessário para a recuperação do capital investido no projeto.

Por sua vez, a análise de sensibilidade visa a identificar as variáveis estratégicas do empreendimento, ou seja, aquelas que mais influenciam na sua rentabilidade. Essa análise funciona como um sinal de alerta para o caráter marginal do projeto, ou seja, para sua vulnerabilidade a pequenos choques nas principais variáveis, que podem tornar inviável o projeto (Noronha, 1981).

A análise foi realizada variando-se, de modo pessimista, um determinado percentual no valor unitário de cada item de saída e entrada do projeto, enquanto os demais itens eram mantidos constantes. $\mathrm{O}$ indicador escolhido como referência foi a TIR. Após cada variação introduzida, foi feita a comparação do valor inicial da TIR com o valor obtido após o "choque".

Rev. Ceres, Viçosa, v. 58, n.2, p. 155-160, mar/abr, 2011 


\section{Fonte dos dados}

O objetivo deste estudo é analisar comparativamente, em termos econômicos os sistemas de cultivo convencional e orgânico de café arábica, voltados aos agricultores familiares do Estado do Espírito Santo. Para o sistema convencional, foram considerados os coeficientes de custo de produção ${ }^{7}$, definidos pelo Centro de Desenvolvimento do Agronegócio - Cedagro. A densidade de plantio foi de 2.976 plantas/ha (espaçamento de $2,80 \mathrm{~m}$ x 1,20m) e a produtividade esperada foi igual a 07 sacas beneficiadas/ha, no $2^{\circ}$ ano, 26 sacas, no $3^{\circ}$ ano e 40 sacas, a partir do $4^{\circ}$ ano.

Para o sistema orgânico, foram considerados os coeficientes de custo de produção do agricultor familiar capi$\mathrm{xaba}^{8}$ que mais avançou e consolidou-se nesse sistema de cultivo, com algumas adaptações e estimativas, principalmente para a fase de implantação da lavoura. A densidade de plantio foi a mesma do convencional e a produtividade esperada igual a 04 sacas beneficiadas/ha, no $2^{\circ}$ ano, 16 sacas, no $3^{\circ}$ ano e 25 sacas, a partir do $4^{\circ}$ ano.

A vida útil das lavouras foi estimada em 15 anos. As benfeitorias consideradas foram apenas as cercas, o terreiro pavimentado e a tulha, por serem básicas para ambos os sistemas de cultivo. A qualidade dos cafés (convencional e orgânico) correspondeu à classificação como tipo 6, bebida dura, com até $12 \%$ de umidade.

\section{RESULTADOS E DISCUSSÃO}

Uma vez elaborados os fluxos de caixa dos sistemas de cultivo de café arábica abordados, foram calculados os indicadores previstos na análise. Os resultados do VPL, às taxas mínimas de atratividade de 6, 10 e 12\% ao ano, bem como da TIR, podem ser observados na Tabela 1 .

Para o café em sistema convencional, observa-se que o VPL foi positivo até a taxa mínima de atratividade de $10 \%$, indicando a viabilidade do cultivo nesse sistema. Mas, à taxa de $12 \%$ esse cultivo passa a ser inviável, já que o VPL foi negativo. Para o café em sistema orgânico, observa-se que o VPL foi positivo até a taxa de $12 \%$, indicando a viabilidade do cultivo nesse sistema em todas as taxas de desconto consideradas.

Pode-se observar, ainda, que os sistemas analisados apresentam TIRs semelhantes, equivalentes a 11,75 e 12,62\% ao ano, para os sistemas convencional e orgânico, respectivamente. Já os "paybacks" econômicos, calculados a partir de uma taxa de desconto de $6 \%$ ao ano, foram de 9,6 anos para o sistema convencional e de 9,3 anos para o orgânico, o que mostra uma diferença muito pequena (de 3,6 meses) nos prazos para recuperação do capital investido, entre esses sistemas de cultivo.

\footnotetext{
Disponíveis em http://www.cedagro.org.br/coeficientes/cafearabica40.html.

${ }^{8}$ Sr. Admir Rossmann, do município de Santa Maria de Jetibá-ES.
}

Portanto, considerando esses indicadores de retorno financeiro, pode-se concluir que os sistemas de cultivo considerados apresentaram viabilidade semelhante, com resultados ligeiramente superiores para o sistema orgânico.

Esses resultados assemelham-se, em parte, aos obtidos por Carmo \& Magalhães (1999), Sarcineli \& Rodriguez (2006) e Caixeta et al. (2009), autores já citados na introdução deste artigo, os quais também demonstraram a viabilidade da produção de café em sistema orgânico, com a diferença de que eles analisaram processos produtivos já realizados em regiões distintas, enquanto este estudo enfocou a viabilidade de um possível investimento na produção.

Sabe-se, porém, que o diferencial de preço entre o café orgânico e o convencional (prêmio do orgânico ${ }^{9}$ ) tem sido, geralmente, o maior estímulo aos cafeicultores familiares para conversão. Assim, retirando-se o referido diferencial (50\% a mais por saca), observou-se que o sistema orgânico passou a ser inviável, economicamente, de acordo com os indicadores utilizados e para todas as taxas mínimas de atratividade fixadas, cujos dados constam na Tabela 1.

Desse modo, ficou evidenciada a dependência de recebimento do referido prêmio para que o cultivo orgânico de café arábica seja viável, em termos econômicos, principalmente porque tal prêmio faz a compensação da produtividade menor $(-37,5 \%)$ que a obtida no sistema convencional.

Nas Tabelas 2 e 3, são apresentados os resultados da análise de sensibilidade, na qual foi introduzida uma variação de mais $10 \%$ no valor unitário de cada item de saída, e de menos $10 \%$ nos preços esperados dos cafés em comparação. Nessas tabelas, podem ser observados os efeitos da variação nos valores unitários dos itens de saída, relativos aos insumos, à mão de obra e aos outros serviços, bem como no preço recebido, sobre a TIR, que foi o indicador escolhido para análise.

Em ambos os sistemas de cultivo, a TIR mostrou-se mais sensível, em ordem, às variações no preço do café, na mão de obra, nos fertilizantes e corretivos, nos outros insumos/serviços e nas mudas. A única diferença é que no sistema convencional constam também os agrotóxicos, posicionados entre outros insumos/serviços e mudas.

A TIR foi quase insensível ao choque no valor das mudas, mas apresentou grande sensibilidade ao choque no valor do preço dos cafés, revelando que o preço é a variável estratégica, tanto no cultivo convencional como no orgânico, já que exerce a maior influência na rentabilidade do cafeicultor. 
Tabela 1. Indicadores da viabilidade financeira dos sistemas de produção orgânico e convencional: valor presente líquido (VPL), em $\mathrm{R} \$$, taxa interna de retorno (TIR), em \%, e payback (PE), em anos

\begin{tabular}{|c|c|c|c|c|c|}
\hline \multirow{2}{*}{ Sistema } & \multicolumn{3}{|c|}{ VPL } & \multirow{2}{*}{ TIR } & \multirow{2}{*}{$\mathbf{P E}$} \\
\hline & $6,00 \%$ & $10,00 \%$ & $12,00 \%$ & & \\
\hline Convencional & $7.709,22$ & $1.916,18$ & $-253,05$ & 11,75 & 9,6 \\
\hline Orgânico $^{1}$ & $10.003,16$ & $3.234,88$ & 697,21 & 12,62 & 9,3 \\
\hline Orgânico $^{2}$ & $-12.497,70$ & $-14.105,33$ & $-14.678,53$ & $-5,38$ & - \\
\hline
\end{tabular}

${ }^{1}$ com diferencial de preço; ${ }^{2}$ sem diferencial de preços.

Tabela 2. Redução da taxa de retorno, em pontos percentuais, decorrente de variações desfavoráveis de $10 \%$ no preço esperado do produto e nos itens de custo - sistema convencional de cultivo de café

\begin{tabular}{lcc}
\hline \multicolumn{1}{c}{ Item } & TIR $(\boldsymbol{\%})$ & Variação $(\boldsymbol{\%})$ \\
\hline Preço esperado do café & 6,40 & $-5,35$ \\
Mão de obra & 9,91 & $-1,84$ \\
Fertilizantes e corretivos & 10,61 & $-1,13$ \\
Outros insumos e serviços & 11,26 & $-0,49$ \\
Agrotóxicos & 11,61 & $-0,14$ \\
Mudas & 11,68 & $-0,07$ \\
\hline
\end{tabular}

Tabela 3. Redução da taxa de retorno, em pontos percentuais, decorrente de variações desfavoráveis de $10 \%$ no preço esperado do produto e nos itens de custo - sistema orgânico de cultivo de café

\begin{tabular}{lcc}
\hline \multicolumn{1}{c}{ Item } & TIR $(\boldsymbol{\%})$ & Variação $\mathbf{( \% )}$ \\
\hline Preço esperado do café & 8,30 & $-4,32$ \\
Mão de obra & 11,30 & $-1,32$ \\
Fertilizantes e corretivos & 11,71 & $-0,91$ \\
Outros insumos e serviços & 12,06 & $-0,56$ \\
Mudas & 12,56 & $-0,06$ \\
\hline
\end{tabular}

Considerando uma taxa referencial de juros de $6 \%$ ao ano, que corresponde ao rendimento oferecido pelas cadernetas de poupança, o cultivo passa a ser inviável, se o preço cair mais de $10,7 \%$, em relação ao esperado para o café convencional, e mais de 14,8\% para o café orgânico.

Verificou-se, também, que efeitos significativos foram produzidos pelo choque no valor da mão de obra, enquanto os efeitos dos choques nos demais itens foram pouco significativos.

Outro aspecto que merece ser discutido refere-se aos desembolsos efetuados para o custeio do café (a partir do $4^{\circ}$ ano), que representam o custo operacional efetivo. Verificou-se que tais desembolsos foram menores no cultivo orgânico. A redução na demanda por insumos externos, conforme preconiza Gliessman (2005), foi decisiva para tanto, estando ela associada também a um aproveitamento mais adequado da mão de obra familiar. Nesse mesmo sentido, também concluíram Carmo \& Magalhães (1999), ao realizarem estudo semelhante com uma gama maior de culturas (incluindo o café), afirmando que: "mais do que o barateamento do custo efetivo, o papel da mão de obra familiar qualifica como principal objetivo da exploração a reprodução da unidade familiar, deixando, muitas vezes, a acumulação de capital strictu sensu em segundo plano. O uso de insumos-materiais internos, por sua vez, representa maior integração entre as atividades da propriedade e, muitas vezes, a substituição de nutrientes de fonte energética não renovável por fontes renováveis. Juntos, significam menor necessidade de capital para reprodução do processo produtivo e menor dependência do mercado no que diz respeito aos meios de produção."

\section{CONCLUSÕES}

O estudo demonstrou que os sistemas convencional e orgânico de produção de café arábica abordados foram economicamente viáveis, considerando as taxas mínimas de atratividade de $10 \%$, para o convencional, e de $12 \%$, para o orgânico. Entretanto, observou-se a grande dependência de recebimento do prêmio para que o cultivo orgânico fosse viável, tendo compensado a sua menor produtividade.

O preço recebido é a variável que exerce a maior influência na rentabilidade do cafeicultor familiar, tanto no cultivo convencional, como no orgânico. A mão de obra exerce influência significativa nesta rentabilidade.

Conclui-se, ainda, que, assegurada a eficiência econômica e ecológica do sistema orgânico, o desafio agora é aperfeiçoar a sua eficiência técnica para que ele possa contribuir, de modo incondicional, com a sustentabilidade dos agricultores familiares do Estado do Espírito Santo. Eis uma relevante missão, que precisa ser mais assumida pelas instituições de pesquisa e extensão rural.

\section{REFERÊNCIAS}

Caixeta GZT, Teixeira SM \& Singulano Filho G (2009) Viabilidade econômica, eficiência e sustentabilidade da cafeicultura familiar na Zona da Mata de Minas Gerais. In: 6 Simpósio de Pesquisa dos Cafés do Brasil, Vitória. Anais, Embrapa Café. CD-ROM.

Carmo MS \& Magalhães MM (1999) Agricultura sustentável: avaliação da eficiência técnica e econômica de atividades agropecuárias selecionadas no sistema não convencional de produção. Informações Econômicas: 29(7):7-98.

Rev. Ceres, Viçosa, v. 58, n.2, p. 155-160, mar/abr, 2011 
Ferrão RG, Fornazier, MJ, Ferrão, MAG, Prezotti, LC, Fonseca, AFA da, Alixandre, FT, Ferrão, LFV (2008) Estado da arte da cafeicultura no Espírito Santo. In: Tomaz MA et al. (Ed). Seminário para a sustentabilidade da cafeicultura. Alegre, UFES. p.29-47.

Giordano SR (2000) Gestão ambiental no sistema agroindustrial. In: Zylbersztajn D \& Neves MF (Org.). Economia e gestão dos negócios agroalimentares: indústria de alimentos, indústria de insumos, produção agropecuária e distribuição. São Paulo, Pioneira. p.255-81.

Giomo GS, Pereira SP \& Bliska FMM (2007). Panorama da cafeicultura orgânica e perspectivas para o setor. O Agronômico, 59: 33-36.,

Gliessman SR (2005) Agroecologia: processos ecológicos em agricultura sustentável. 3.ed. Porto Alegre, UFRGS. 653p.
Herszkowicz N (2009) Ameaças e oportunidades para os cafés do Brasil. In: Tomaz MA et al. (Ed). Seminário para a sustentabilidade da cafeicultura. Alegre, UFES. p.271-88.

Lapponi JC (2000) Projetos de investimento: construção e avaliação do fluxo de caixa - modelos em Excel. São Paulo, Lapponi. $378 \mathrm{p}$.

Noronha JF (1981) Projetos agropecuários: administração financeira, orçamentação e avaliação econômica. Piracicaba, FEALQ. $274 \mathrm{p}$.

Sarcinelli O \& Rodriguez EO (2006) Análise do desempenho econômico e ambiental de diferentes modelos de cafeicultura em São Paulo - Brasil: estudo de caso na região cafeeira da Média Mogiana do Estado de São Paulo. Revista Iberoamericana de Economía Ecológica, 5:13-26. 